Revista Científica General José María Córdova

(Revista Colombiana de Estudios Militares y Estratégicos)

Bogotá D.C., Colombia

ISSN 1900-6586 (impreso), 2500-7645 (en línea)

Web oficial: https://www.revistacientificaesmic.com

\title{
Principios clave para el uso de la fuerza en escenarios urbanos en Colombia
}

\author{
Jaime Cubides-Cárdenas \\ https://orcid.org/0000-0002-6542-6892 \\ jacubides@ucatolica.edu.co \\ Universidad Católica de Colombia, Bogotá D.C., Colombia \\ Juan David González Agudelo \\ https://orcid.org/0000-0002-4034-003X \\ juand.gonzalez@upb.edu.co \\ Universidad Pontificia Bolivariana, Medellín, Colombia

\section{Fernanda Navas-Camargo} \\ https://orcid.org/0000-0002-4032-7070 \\ johanna.navas@esdegue.edu.co \\ Escuela Superior de Guerra "General Rafael Reyes Prieto”, Bogotá D.C., Colombia
}

Citación APA: Cubides-Cárdenas, J., González Agudelo, J. D., \& Navas-Camargo, F. (2022). Principios clave para el uso de la fuerza en escenarios urbanos en Colombia. Revista Cientifica General José María Córdova, 20(37), 89-107.

https://dx.doi.org/10.21830/19006586.808

Publicado en línea: $1 .^{\circ}$ de enero de 2022

Los artículos publicados por la Revista Cientifica General José María Córdova son de acceso abierto bajo una licencia Creative Commons: Atribución - No Comercial - Sin Derivados.

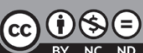

Para enviar un artículo:

https://www.revistacientificaesmic.com/index.php/esmic/about/submissions
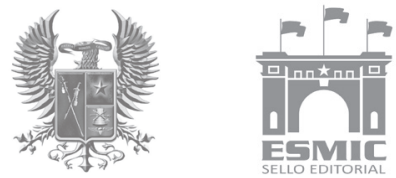

\section{Miles Doctus}




\title{
Principios clave para el uso de la fuerza en escenarios urbanos en Colombia
}

\section{Key principles for the use of force in urban scenarios in Colombia}

\author{
Jaime Cubides-Cárdenas \\ Universidad Católica de Colombia, Bogotá D.C., Colombia
}

Juan David González Agudelo

Universidad Pontificia Bolivariana, Medellín, Colombia

\section{Fernanda Navas-Camargo}

Escuela Superior de Guerra “General Rafael Reyes Prieto”, Bogotá D.C., Colombia

RESUMEN. Este artículo analiza los parámetros y principios para el uso de la fuerza legítima del Estado en escenarios urbanos en Colombia, ante la amenaza híbrida actual. Con base en una investigación cualitativa con enfoque empírico, primero se ilustra la naturaleza de la amenaza híbrida en Colombia. Luego se examina el fundamento doctrinal para emplear la fuerza de los cuerpos de seguridad en el conflicto colombiano. Posteriormente se analizan los principios del derecho internacional humanitario para conducir hostilidades en escenarios urbanos, con observancia a los ecosistemas criminales. Finalmente se desarrollan los principios de necesidad y proporcionalidad, entre otros, en otras situaciones de violencia. Se concluye que hay principios clave, pero aún no suficientes, para orientar el uso de la fuerza en escenarios urbanos de Colombia.

PALABRAS ClAVE: conflicto armado; derecho humanitario; defensa; derecho operacional; guerra urbana

AвstraCt. This article analyzes the parameters and principles for using legitimate state force in urban scenarios in Colombia in the face of the current hybrid threat. First, qualitative research with an empirical approach is used to illustrate the nature of Colombia's hybrid threat and examine the doctrinal basis for the use of force by security forces in the Colombian conflict, then analyze the principles of international humanitarian law for hostilities in urban scenarios, observing criminal ecosystems. Finally, the principles of necessity and proportionality, among others, in other violent situations are developed, concluding that key principles exist; however, they are insufficient to guide the use of force in urban scenarios in Colombia.

KEYwORDS: armed conflict; defense; humanitarian law; operational law; urban warfare

Sección: Seguridad y Defensa • Artículo de investigación científica y tecnológica

Recibido: 3 de mayo de 2021 • Aceptado: 16 de noviembre de 2021

Contacto: Jaime Cubides-Cárdenas $\bigotimes$ jacubides@ucatolica.edu.co 


\section{Introducción}

La guerra urbana no es un fenómeno nuevo. En efecto, a lo largo de los siglos, los conflictos urbanos han tendido a ser más la regla que la excepción. Debe recordarse que las guerras del pasado se centraron en asedios y la defensa de los centros urbanos, mientras que las grandes batallas en los siglos recientes han sido excepcionales. Así lo explica Álvarez (2017, pp. 24-25) con el ejemplo de la antigua ciudad de Hamoukar. Ubicada en el actual norte de Siria, los arqueólogos han descubierto allí evidencias de combate urbano hace 5500 años.

En este sentido, hay pocas razones para creer que los conflictos futuros no involucrarán también algún tipo de guerra urbana. $\mathrm{Al}$ respecto, actualmente sigue existiendo un reto para implementar el uso de la fuerza por parte de los cuerpos de seguridad de los Estados, especialmente en Colombia, donde hay escenarios hostiles urbanos. Por ese motivo, la estrategia y política de defensa en Colombia debe replantearse, ya que la apertura de las fronteras geográficas está ocasionando que lugares geoestratégicos sean captados por ecosistemas criminales urbanos, los cuales aprovechan la infraestructura del Estado. En consecuencia, el tradicional combate terrestre y la conducción de hostilidades y otras misiones militares, ya sea en tiempos de guerra, de transición, estabilización o paz, representa un reto de seguridad en cuanto al uso de la fuerza para los líderes políticos y mandos responsables de la fuerza pública, dado que el control territorial ha trascendido el entorno de la guerra regular.

En cuanto a los actores del conflicto en el contexto de Colombia, se encuentran tres grandes tipos: los grupos armados organizados, los grupos delictivos organizados y la delincuencia organizada transnacional y terrorista.

- Los grupos armados organizados (GAO) son aquellos que, bajo la dirección de un mando responsable, ejercen sobre una parte del territorio un control tal que les permite realizar operaciones militares sostenidas y concertadas. Además, cumplen con los criterios objetivos para ser denominados GAO según el Protocolo II adicional a los Convenios de Ginebra: 1) uso de violencia armada contra la fuerza pública u otras instituciones del Estado, la población civil, bienes civiles o contra otros grupos armados; 2) capacidad de generar un cierto nivel de violencia armada; 3) una organización y un mando que ejerce liderazgo o dirección sobre sus miembros, lo que les permite usar la violencia contra los objetivos mencionados en el territorio nacional (Comité Internacional de la Cruz Roja [CICR], 1977b, artículo 1).

- Los grupos delictivos organizados (GDO) son grupos estructurados de tres o más personas que existen durante cierto tiempo y actúan concertadamente con el propósito de cometer uno o más delitos, con miras a obtener directa o indirectamente un beneficio económico u otro beneficio de orden material de los 
tipificados en el Código Penal Colombiano (Ministerio de Defensa Nacional [Mindefensa], 2016a).

- Finalmente, la delincuencia organizada transnacional y terrorista (DOT) se refiere a grupos estructurados de tres o más personas que existen durante cierto tiempo y que actúan concertadamente con el propósito de cometer uno o más delitos graves o delitos tipificados con arreglo a la Convención de Palermo, con miras a obtener, directa o indirectamente, un beneficio económico u otro beneficio de orden material. Tiene el carácter de transnacional si a) se comete en más de un Estado; b) se comete dentro de un solo Estado, pero una parte sustancial de su preparación, planificación, dirección o control se realiza en otro Estado; c) se comete dentro de un solo Estado, pero entraña la participación de un grupo delictivo organizado que realiza actividades delictivas en más de un Estado; o d) se comete en un solo Estado, pero tiene efectos sustanciales en otro (Ley 800, 2003).

Estos actores conforman ecosistemas criminales que poseen dos cualidades únicas que crean dificultades en las operaciones de los servicios de seguridad: primero, se ubican en zonas densamente pobladas; y segundo, las ciudades hoy tienen múltiples conurbaciones con espacios tridimensionales desordenados, que representan importantes desafíos logísticos y de navegación para la persecución (Álvarez \& Rodríguez, 2018, p. 21).

En este sentido, el uso de la fuerza, conforme al derecho humanitario bélico, es un recurso de necesidad militar clave, por lo cual las discusiones actuales deben trascender los debates tradicionales sobre conflictos armados no internacionales transfronterizos, con desbordamiento y transnacionales. Es decir, se hace necesaria la comprensión extensiva que permita explorar nuevas dimensiones, fundamentalmente para garantizar la conducción de las hostilidades por parte de quienes participan directamente con arreglo a las normas del Derecho Internacional Humanitario (DIH). Esto es notoriamente importante en escenarios urbanos del conflicto armado interno y otras situaciones de violencia en estos contextos, dado que allí existen múltiples amenazas y riesgos de naturaleza divergente.

\section{Naturaleza de la amenaza híbrida en Colombia}

Como se ha dicho, gran parte de los enfrentamientos bélicos contemporáneos se desarrollan en escenarios hostiles urbanos, ya que allí convergen el crimen organizado transnacional, la insurgencia, el terrorismo, guerra no convencional, guerra irregular, guerra asimétrica, guerra de criminales, guerra limitada, guerra no trinitaria, guerra de tres bloques, guerra de cuarta generación, guerra en red, eco-yihad, guerra de información, guerra financiera, guerra de los recursos, guerra jurídica, guerra cibernética y guerra caótica. Esta convergencia hace razonable aceptar la complejidad y la vigencia de la violencia urbana. 
En este sentido, la tradicional estrategia y política de seguridad y defensa, que se planteaba en términos de lo interno y lo externo, hoy se está reconfigurando de forma constante para poder enfrentar las estructuras en redes en el marco de los conflictos armados no internacionales (CANI) y otras situaciones de violencia. La fuerza pública, en especial Policía y Ejército, enfrentan hoy más que nunca la complejidad de estas amenazas en ambientes multidimensionales, por lo cual no se circunscriben a un evento meramente externo o interno.

En consecuencia, esto nos pone frente a una amenaza híbrida, como la denomina Frank Hoffman (2009), pues los actores del conflicto tienen una adaptativa mezcla de armas convencionales, tácticas irregulares, terrorismo y comportamiento criminal en el espacio de batalla, donde el fin primordial ya no reside en alcanzar unos objetivos políticos. Por esto último, el parámetro interno o externo ya no resulta determinante para los entes criminales, pero sí afecta la caracterización y acción por parte de los servicios de seguridad del Estado en el momento de elegir los métodos y reglas de combate. Incluso, para ir más allá, hoy todos los cuerpos de seguridad, tanto policivos como militares, aplican el concepto de "operaciones de guerra urbana".

Según lo expuesto, vale la pena analizar el caso del Estado colombiano, pues, conforme a la Constitución colombiana, la Policía Nacional está formalmente subordinada al Ministerio de Defensa y, conjuntamente con las Fuerzas Militares, constituye la fuerza pública del país. Esta estructura institucional, por sí misma, no contraviene ningún estándar internacional; incluso ambos desarrollan operaciones de seguridad interior en ámbitos urbanos, sin mayores conflictos de interés.

Aquí se pueden destacar los batallones de operaciones terrestres y los batallones de fuerzas especiales urbanas del Ejercito Nacional, además del Grupo Especial de Operaciones de la Policía Nacional, e incluso los grupos Gaula militares y policiales creados exclusivamente para evitar y actuar en contra del secuestro y la extorsión. Todas estas organizaciones desarrollan acciones en el contexto de la guerra urbana, semiurbana y rural, sin necesidad de hablar de eventos internos o externos, a raíz del fenómeno polemológico de la divergente naturaleza de los actores en la actualidad (GAO, GDO y DOT). Ante este fenómeno, los cuerpos de seguridad deben desarrollar acciones coordinadas en escenarios hostiles urbanos.

Por ello, esta situación presenta dos grandes retos y desafíos. El primero es el uso de armas explosivas en zona pobladas, lo cual, conforme al CICR (2015) y los principios del $\mathrm{DIH}$, impone límites en el uso de la fuerza, particularmente bajo el principio de proporcionalidad y precaución en el ataque. Esta situación está regulada para los CANI y otras situaciones de violencia, con la finalidad de proteger a la población.

El segundo desafío reside en las garantías jurídicas operacionales para los miembros de la fuerza púbica. Los nuevos manuales y ediciones del DIH no traen consigo ni aluden a estándares para usar la fuerza en contextos urbanos, lo que evidencia una limitación para garantizar la soberanía y proteger de amenazas los intereses nacionales desde la política de seguridad y defensa nacional. 
Estas afirmaciones no tienen explicación epistemológica desde las actuales disciplinas sociales y los desarrollos académicos, pues parten de una observación empírica de este fenómeno político y social en el contexto regional. En particular, este artículo aborda el caso de Colombia. En este caso, las acciones militares se desarrollan en un ambiente complejo y multidimensional, regulado actualmente por el Derecho Operacional (Mindefensa, 2015), la Directiva Permanente 015 de Mindefensa (2016a) y la Sentencia C-674 de 2017 de la Corte Constitucional. Bajo estos estándares, en el actual CANI se regula el uso de la fuerza contra GAO, GDO y GOT siguiendo los principios del DIH. Frente a otras situaciones de violencia, las acciones militares se limitan por los estándares de la Organización de las Naciones Unidas (ONU) para el empleo de la fuerza bajo la lógica del respeto a los derechos humanos, regulados por los Principios básicos sobre el empleo de la fuerza y de armas de fuego por los funcionarios encargados de hacer cumplir la ley (ONU, 1990) y el Código de conducta para funcionarios encargados de hacer cumplir la ley (ONU, 1979).

En consecuencia, como se ha dicho, el uso de la fuerza en las operaciones militares es un reto de seguridad para los mandos responsables, por cuanto no existen garantías jurídico-operacionales para el uso de la fuerza letal más allá del CANI y de los principios del DIH.

A su vez, se evidencia la prevalencia del etnocentrismo norteamericano desde el paradigma del realismo político, que sigue enfocado hoy en la teoría de las relaciones internacionales y los estudios en seguridad, pues estos argumentos se encuentran en algunas clasificaciones de conflictos utilizadas por el Departamento de Defensa de Estados Unidos $^{1}$. Este artículo también toma como referencia una investigación previa sobre el uso de la fuerza en el contexto colombiano (Cubides et al., 2019).

\section{Normativa aplicable a la participación directa en hostilidades en escenarios urbanos}

La normativa aplicable a la participación directa en las hostilidades es el artículo 3 común y el Protocolo II adicional de los Convenios de Ginebra (CICR, 1949a; 1977b); no obstante, esta figura no está definida en ninguna otra disposición de los Convenios de Ginebra de 1949 ni en tratados anteriores, salvo el artículo 15 del Convenio IV, que plantea la posibilidad de establecer zonas neutrales para alojar, entre otras, a las personas civiles que no participen en las hostilidades y que no realicen trabajo alguno de índole militar durante su estancia en esas zonas (CICR, 1949b). Sin embargo, la distinción entre las personas que participan directamente en las hostilidades y las personas que han dejado de hacerlo es un elemento fundamental del derecho humanitario, pues de allí se derivan

1 Por ejemplo: 1) conflictos de Alta Intensidad o guerras convencionales; 2) conflictos de Media Intensidad o guerra de guerrillas; y 3) conflictos de Baja Intensidad. Esta categoría se usa en centros de pensamiento como el Heidelberg Institute for International Conflict Research en su barómetro de conflictos anual (2019). 
las obligaciones mínimas a las que deben sujetarse las partes de un CANI. Este principio de distinción se desarrolla en dicho artículo 3 común, tanto la prohibición de ejecutar determinados actos que atenten contra la vida, integridad corporal, libertad y dignidad personal de los no combatientes (numeral 1, literales a, b, c y d) como la obligación de asistir a los heridos en combate (numeral 2) (CICR, 1949a).

El propósito de la referencia a la participación directa en las hostilidades que figura en los protocolos adicionales es determinar cuándo un civil se convierte en un objetivo lícito conforme al derecho humanitario durante la conducción de las hostilidades. El alcance y la aplicación de la noción de participación directa en las hostilidades es objeto de debate en el marco de las normas para la conducción de hostilidades (Melzer, 2010).

\section{Artículo 3 común a los Convenios de Ginebra en clave del derecho a la vida}

El artículo 3 común a los Convenios de Ginebra ha cristalizado el derecho internacional consuetudinario, en cuanto dispone que "las personas que no participen directamente en las hostilidades, incluidos los miembros de las fuerzas armadas que hayan depuesto las armas y las personas puestas fuera de combate por enfermedad, herida, detención o por cualquier otra causa [...]" han de ser protegidas (CICR, 1949a). Esto también tiene un complemento en el artículo 4.1 del Protocolo Adicional II (CICR, 1977b), puesto que este estipula una regla similar para proteger a las personas en los conflictos armados modernos.

Por lo anterior, estas normas son las más importantes en el DIH, dado que establecen prohibiciones frente a las personas que no participan directamente en las hostilidades. Quizás es lo más sustancial, puesto que permite evidenciar el núcleo más duro de convergencia entre el DIH y los derechos humanos. Ambos cuerpos normativos constituyen unos derechos humanos mínimos, si los vemos en positivo. A continuación se citan las únicas cuatro cosas que prohíbe el DIH, que son aplicables específicamente al CANI y otras situaciones de violencia:

a) los atentados contra la vida y la integridad corporal, especialmente el homicidio en todas sus formas, las mutilaciones, los tratos crueles, la tortura y los suplicios;

b) la toma de rehenes;

c) los atentados contra la dignidad personal, especialmente los tratos humillantes y degradantes;

d) las condenas dictadas y las ejecuciones sin previo juicio ante un tribunal legítimamente constituido, con garantías judiciales reconocidas como indispensables por los pueblos civilizados. (CICR, 1949a)

En otras palabras, este es el núcleo más básico de interacción entre los cuerpos normativos del DIH y los derechos humanos, ya que busca garantizar y proteger a la persona humana en función del derecho a la vida. En consecuencia, estos derechos fundamentales se deben respetar en todas las circunstancias por los Estados; incluso en casos de conflicto o de disturbios. 
No obstante, se precisa advertir que el artículo 3 común no aborda la conducción de las hostilidades. Las protecciones sustanciales que confiere en sí mismas son la prohibición de la tortura y la toma de rehenes, pues estas implican cierto grado de control sobre las personas que están en poder de una parte en el conflicto. Esto incluye a los civiles que viven en zonas controladas por un actor del conflicto, pero no se refiere a las acciones de las partes regidas por las normas sobre la conducción de hostilidades.

Por otro lado, la única protección que ha dado lugar a dudas es la prohibición del homicidio. En algunos casos, se ha hallado que se aplica a los ataques ilícitos en la conducción de hostilidades. Por tanto, si este fuera el caso, la prohibición del homicidio debería interpretarse a la luz de las normas específicas sobre la conducción de hostilidades, en particular las normas sobre distinción, proporcionalidad y precauciones. De esta forma, el acto de dar muerte a una persona, siempre y cuando se ajuste a las normas sobre conducción de hostilidades, no constituiría homicidio en virtud del artículo 3 común (Corte Penal Internacional, 2014).

\section{Fundamento doctrinal para el empleo de la fuerza de los cuerpos de seguridad en el CANI colombiano}

Las Fuerzas Militares, en su accionar operacional, tienen una capacidad moderna y profesional afianzada en la doctrina y los procesos. Esto ha perfeccionado su capacidad de neutralizar y debilitar sistemáticamente las amenazas regionales y nacionales que afectan la seguridad del Estado. De esta manera, ha forzado a los actores del conflicto y criminales a negociar bajo el imperio de la ley.

Esta capacidad militar del cuerpo de seguridad del Estado, especialmente del Ejército Nacional de Colombia, tiene su fundamento en la doctrina actual, que emplea el concepto de uso de la fuerza bajo el precepto del derecho operacional terrestre establecido en el Manual Fundamental del Ejército 6-27 (Mindefensa, 2016b): "[el derecho operacional terrestre] se interrelaciona con todos los Manuales Fundamentales del Ejército (MFE), ya que determina el marco jurídico en el cual se desarrollan las operaciones militares como funciones propias del Ejército Nacional" (p. 7).

Además, permite integrar nuevos conceptos políticos y militares a la sinergia operacional, como la llamada acción unificada entre los poderes públicos. Esto se fundamenta en las relaciones cívico-militares, donde el Ejército busca el apoyo de la defensa a la autoridad civil (Manual Fundamental del Ejército 3-28) y la estabilidad (Manual Fundamental del Ejército 3-07) (Mindefensa, 2017a; 2017b). Lo que se busca finalmente es crear las condiciones para que la población pueda reconstruir el tejido social y así avanzar en el control institucional del territorio, bajo la protección del DIH y los derechos humanos. 


\section{La debida diligencia: estrategia para evitar uso desproporcionado de la fuerza}

Como se ha mostrado, el artículo 3 común tiene especial relación con el derecho a la vida, por lo cual el Estado debe brindar un trato humano a las personas que no participen directamente en las hostilidades o que queden fuera de combate por cualquier razón, dado que se prohíben en cualquier tiempo y lugar los atentados a la vida y la integridad personal, especialmente a la luz de los principios del DIH.

En este sentido, el principio de distinción, de acuerdo con lo establecido por la Corte Interamericana de Derechos Humanos (Corte IDH), es una norma consuetudinaria para conflictos armados que establece lo siguiente: "Las partes en conflicto deberán distinguir en todo momento entre personas civiles y combatientes"; "Los ataques solo podrán dirigirse contra combatientes", y "Los civiles no deben ser atacados" (Corte IDH, 2012, párr. 212). Del mismo modo, el párrafo 2 del artículo 13 del Protocolo II prohíbe que tanto las personas civiles como la población civil sean objeto de ataques (CICR, 1977b).

Por su parte, el principio de precaución es otra norma consuetudinaria para conflictos armados que determina lo siguiente: "Las operaciones se realizarán con un cuidado constante de preservar a la población civil, a las personas civiles y los bienes de carácter civil", y se "tomarán todas las precauciones factibles para evitar o reducir en todo caso a un mínimo, el número de muertos y heridos entre la población civil, así como los daños a bienes de carácter civil, que pudieran causar incidentalmente" (Corte IDH, 2013, párr. 216).

Del mismo modo, la norma 17 de DIH consuetudinario del libro de Henckaerts y Doswald-Beck (2007) dispone lo siguiente:

Las partes en conflicto deberán tomar todas las precauciones factibles en la elección de los medios y métodos de guerra para evitar, o reducir en todo caso a un mínimo, el número de muertos y de heridos entre la población civil, así como los daños a los bienes de carácter civil, que pudieran causar incidentalmente. (p. 65)

A su vez, la norma 18 señala:

[...] las partes en conflicto deberán hacer todo lo que sea factible para evaluar si el ataque causará incidentalmente muertos o heridos entre la población civil, daños a bienes de carácter civil o ambas cosas, que sean excesivos en relación con la ventaja militar concreta y directa prevista. (Henckaerts \& Doswald-Beck, 2007, p. 67)

En concordancia con lo anterior, el DIH y el uso de la fuerza en el marco del CANI de Colombia requieren buscar un equilibrio constante entre los principios de la necesidad militar y de la humanidad, que son el fundamento del principio de distinción, dado que permite llevar a cabo operaciones militares bajo el criterio de que representen una ventaja 
militar definida, siempre y cuando no afecten la humanidad de quienes no participan directamente en las hostilidades.

En ese sentido, de acuerdo con el artículo 3.1 común: "las personas que no participen directamente en las hostilidades, incluidos los miembros de las fuerzas armadas que hayan depuesto las armas y las personas puestas fuera de combate por enfermedad, herida, detención o por cualquier otra causa [...]" han de ser protegidas (CICR, 1949a). El artículo 4.1 del Protocolo II complementa la disposición anterior. Por este motivo está prohibido causar sufrimientos, heridas o destrucción que no sean necesarios para el logro de fines militares legítimos.

\section{El homicidio intencional: infracción al DIH, recurso militar de uso de la fuerza}

El crimen de homicidio intencional constituye una infracción a los Convenios de Ginebra, como lo estipulan los artículos 50 del Convenio I, 51 del Convenio II, 130 del Convenio III y 147 del Convenio IV. En virtud del artículo 21 del Estatuto de Roma, el derecho aplicable por parte de esta Corte comprende normas del derecho internacional y tratados aplicables. Por esa razón, cabe remitirse a lo que la Corte IDH ha determinado en su sentencia sobre el caso de las comunidades afrodescendientes desplazadas de la cuenca del río Cacarica: la vida es "el presupuesto esencial para el ejercicio de los demás derechos" (Corte IDH, 2013, párr. 217). Por ello se afirma que las conductas de homicidio intencional y asesinato revisten mayor gravedad, pues carece de sentido abordar los demás derechos desprovistos de la vida.

Es preciso, entonces, resaltar que los actos de homicidio intencional y asesinato cometidos con suma gravedad pueden ser considerados crímenes de lesa humanidad, ya que estos crímenes privan a la víctima de gozar de la vida y afectan a los familiares, no solo por privarlos de la víctima, sino también por el impacto que genera presenciar la muerte, que no se puede subestimar. Las secuelas psicológicas afectan de manera grave a las familiares de víctimas de estos crímenes, lo que se suma a la ausencia que deben soportar y la impotencia de no poder resistir el daño final por temor a represalias (Corte IDH, 2013, párr. 217). Ello permite observar que esta vulneración es de suma gravedad. Por las razones expuestas, se deben ubicar estos graves crímenes en una primera categoría, con base en el carácter fundamental del derecho a la vida, considerada como una condición necesaria para gozar de los demás derechos (Corte IDH, 2013, párr. 217).

En consecuencia, el homicidio intencional como infracción al DIH, en el marco de los Convenios de Ginebra y como recurso militar de uso de la fuerza para los cuerpos de seguridad, no puede estar amparado bajo ninguna circunstancia. Un ejemplo de ello se encuentra cuando los actores armados utilizan personas como escudos humanos, esto es, cuando recurren a la "presencia de una persona civil u otra persona protegida para poner ciertos puntos, zonas o fuerzas militares a cubierto de operaciones militares" (Henckaerts \& Doswald-Beck, 2007, p. 384). Esta obligación se extiende a los CANI, dado que la 
"población civil y las personas civiles gozarán de protección general contra los peligros procedentes de operaciones militares" (Henckaerts \& Doswald-Beck, 2007, p. 385).

Además, de acuerdo con Werle (2005, p. 561), el Tribunal Penal Internacional para la ex-Yugoslavia (TPIY) calificó acertadamente como igualmente punible, conforme al derecho internacional consuetudinario, el uso de escudos humanos en los CANI, específicamente en la norma 97, por la cual "queda prohibida la utilización de escudos humanos" (Werle, 2005, p. 561; Henckaerts \& Doswald-Beck, 2007, p. 384).

Así, dado que el homicidio intencional no está amparado en ningún caso para el uso de la fuerza por parte de los cuerpos de seguridad, no es posible bajo ninguna circunstancia, sin importar las condiciones existentes de tiempo, modo y lugar, eludir las obligaciones que impone el $\mathrm{DIH}$, particularmente los principios de proporcionalidad y precaución en el ataque. Así, "aun si la parte defensora recurriera ilícitamente al uso de escudos humanos, la parte atacante no podrá eludir las obligaciones que le impone el DIH" bajo el principio de no reciprocidad (Melzer, 2019, pp. 94-95).

\section{Principios del DIH para conducir hostilidades en escenarios urbanos, con especial observancia a los ecosistemas criminales}

A la luz del principio de distinción, se debe evitar o por lo menos reducir al máximo los dańos a la población civil y los bienes protegidos. Este criterio se aplica tanto a la parte atacante en el conflicto, que debe hacer todo lo posible para evitar ataques por error o daños incidentales como resultado de sus propias operaciones (precauciones en el ataque), como a la parte que es atacada, que debe adoptar las medidas necesarias para proteger a la población civil bajo su control contra los efectos de los ataques enemigos (precauciones contra los efectos de los ataques) (Melzer, 2019, p. 111).

Esto implica, por ejemplo, que la parte atacante debe tomar precauciones en la elección de métodos y medios de guerra para evitar en lo posible daños incidentales a la población y bienes civiles (Melzer, 2019, p. 113). También implica que las partes en conflicto tienen el deber de evitar situar objetivos militares en el interior o cerca de zonas densamente pobladas, así como de alejar a los civiles y a los bienes civiles de los objetivos militares (Melzer, 2019, p. 114).

Por su parte, el principio de proporcionalidad prohíbe los ataques cuando se pueda prever que causarán incidentalmente daños a bienes de carácter civil que sean excesivos respecto de la ventaja militar definida (Melzer, 2019, p. 112). De ser así, quienes preparen o decidan el ataque deben abstenerse de iniciarlo (Melzer, 2019, p. 113). Al respecto, de forma frecuente se usan medios de combate como armas largas, lanzagranadas y artefactos explosivos improvisados que son poco precisos, lo cual hace que la probabilidad de causar daño a la población y a bienes civiles sea notoriamente alta. 


\section{Ataques a la población civil: un medio de combate de terror de los ecosistemas criminales en Colombia}

De acuerdo con la norma 2 del DIH consuetudinario: "quedan prohibidos los actos o las amenazas de violencia cuya finalidad principal sea aterrorizar a la población civil" (Henckaerts \& Doswald-Beck, 2007, p. 9). Además, el numeral 2 del artículo 13 del Protocolo II prescribe que "no serán objeto de ataque la población civil como tal, ni las personas civiles. Quedan prohibidos los actos o amenazas de violencia cuya finalidad principal sea aterrorizar a la población civil" (CICR, 1977b). En el mismo sentido se pronuncia el artículo 4.2 de este protocolo.

Gerhard Werle (2005), por su parte, considera el terrorismo como un método de combate prohibido, cuyo uso constituye una infracción a los Convenios de Ginebra. No obstante, no existe una disposición que se corresponda con lo anterior en el artículo 8.2 del Estatuto de Roma, que establece los Convenios de Ginebra en los CANI, por lo que no pueden ser objeto de acusación por esta razón. Así, la mayoría de la Triol Chamber del TPIY en el caso Galio consideró que existe responsabilidad penal individual por terror contra la población civil cuando tengan como consecuencia su muerte o atenten contra su integridad física o su salud (Werle, 2005, p. 529).

Dicho crimen se constituye por los siguientes elementos: 1) actos de violencia dirigidos contra la población civil o civiles; 2) el delincuente hizo intencionalmente que la población civil o los civiles individuales que no participan directamente en las hostilidades sean objeto de esos actos de violencia; 3) el delito se cometió con el objetivo principal de difundir el terror entre la población civil (Werle, 2005, p. 530).

Por otro lado, el DIH reconoce "los derechos a la vida, a la integridad física, la libertad y seguridad personales" como objeto de protección, por lo cual prohíbe los atentados contra dichos derechos de los civiles conforme al artículo 3 común. El acto terrorista trasciende la víctima, y genera en los demás ciudadanos la idea de ser eventuales víctimas. Esta situación de temor, alarma e inseguridad lesiona los derechos individuales de las víctimas y a su vez genera inseguridad colectiva, lo que impide o complica el ejercicio de los derechos (Pérez \& Acevedo, 2010, p. 45).

En definitiva, quien participe directamente en las hostilidades puede convertirse en terrorista si su accionar violento está sistemáticamente orientado a generar terror en la población civil (Valencia, 2013, p. 406). De acuerdo con esta definición, los actores del CANI (GAO, GDO y GOT) desarrollan acciones para causar terror como medio de combate prohibido, mediante el reclutamiento de menores, los desplazamientos forzados, ataques armados contra la fuerza pública, secuestros extorsivos y asesinato de líderes sociales. Estos crímenes se configuran en la medida en que causan lesiones a la población civil mediante dichos actos de violencia. 


\section{Ataques indiscriminados a los bienes de carácter civil: estrategia de guerra de los ecosistemas criminales}

El artículo 52.1 del Protocolo I establece que "los bienes de carácter civil no serán objeto de ataques ni de represalias" (CICR, 1977a). Sin embargo, no existe una disposición que lo prohíba en el CANI. No obstante, el TPIY ha señalado la importancia de proteger objetos civiles tanto en conflictos armados internacionales como en CANI y, en consecuencia, ha determinado la prohibición absoluta de ataques contra dichos objetos (Werle, 2005). En suma, la norma que, por ejemplo, prohíbe atacar lugares de culto, que se considera consuetudinaria para conflictos internacionales, ahora también se considera así para los CANI.

De igual manera, en cuanto a los bienes civiles en relación con el uso de la fuerza, se afirma que son "aquellos objetos que por su naturaleza, ubicación, finalidad o utilización contribuyan eficazmente a la acción militar o cuya destrucción total o parcial, captura o neutralización ofrezca en las circunstancias del caso una ventaja militar definida" (Henckaerts \& Doswald-Beck, 2007, p. 34). La palabra "definida" sugiere que la ventaja debe ser concreta y perceptible, y no hipotética o especulativa (Melzer, 2019, p. 101).

La obligación establecida no puede dejar de cumplirse y no establece excepción, por lo cual la prohibición no se exceptúa en caso de necesidad militar imperiosa y mientras no exista otra alternativa prácticamente posible para obtener una ventaja militar equivalente. Solo puede invocarse una derogación fundada en una necesidad militar imperiosa cuando el bien, por su función, haya sido transformado en un objetivo militar (Henckaerts \& Doswald-Beck, 2007, p. 144). En consecuencia, casi nunca puede invocarse la necesidad militar para justificar un ataque a los bienes de naturaleza civil, ya que por regla general existen otras alternativas para eludir dichos bienes (Valencia, 2013, p. 472).

\section{Uso de la fuerza en otras situaciones de violencia}

En general, en muchos Estados se comprende que los cuerpos policiales son los competentes y encargados del manejo de situaciones internas, disturbios, manifestaciones y protestas; sin embargo, no existe una prohibición para que las fuerzas militares lleven a cabo este tipo de tareas. Aunque actualmente hay múltiples situaciones que involucran más a la policía en operaciones de control del orden público, no solo en áreas rurales, sino también urbanas, integrándose a acciones operacionales bajo los preceptos del DIH y los derechos humanos, lo mismo sucede con las Fuerzas Armadas.

En Colombia, en principio, la Policía Nacional no es la única institución con competencias para mantener el orden público en contextos de protesta social, manifestaciones y disturbios, razón por la cual las Fuerzas Armadas pueden apoyar esta labor por medio de la "asistencia militar". Notoriamente, esta figura se encuentra consagrada de forma 
muy reciente en el ordenamiento jurídico, fundamentada en el artículo 170 del Código Nacional de Seguridad y Convivencia Ciudadana (Ley 1801, 2016), el cual estipula que es un mecanismo de naturaleza temporal y excepcional ante "graves alteraciones de la seguridad y la convivencia o para afrontar calamidades públicas".

Es importante precisar que, en situaciones de conflicto armado, los militares están sujetos a la normativa del DIH, pero cuando estas fuerzas son llamadas a apoyar a la Policía Nacional en el restablecimiento del orden en medio de protestas sociales desbordadas, no se aplica este ordenamiento jurídico, sino que recae sobre el servidor público la obligación de cumplir los preceptos y estándares de los derechos humanos, como bien lo señala el Manual de Derecho Operacional 3-41 (Mindefensa, 2015).

\section{Necesidad y proporcionalidad, principios claves en otras situaciones de violencia}

En un escenario de aplicación del DIH, las partes en conflicto tienen como objetivo debilitar a las fuerzas militares del enemigo, para lo cual usan la fuerza letal contra objetivos militares como primer recurso, en concordancia con los métodos y medios autorizados por las normas del DIH. En cambio, frente a la necesidad de mantener o restablecer el orden público, el uso de la fuerza letal puede emplearse única y exclusivamente como último recurso. De ahí que existan dos principios similares tanto en el DIH como en los derechos humanos, como es el caso de la necesidad y la proporcionalidad.

El principio de necesidad militar en conflictos armados está relacionado con que toda actividad de combate debe justificarse y, por lo tanto, están prohibidas las acciones que no sean necesarias. Es posible realizar un ataque directo mientras este represente una ventaja militar directa, prevista y concreta. Por el contrario, en situaciones de mantenimiento y restablecimiento del orden público, el principio de necesidad se entiende como la utilización de los medios no violentos antes de hacer uso directo de la fuerza y de las armas de fuego. Estos mecanismos solo podrán utilizarse cuando las primeras medidas resulten ineficaces o no garanticen el logro del resultado previsto.

Entretanto, el principio de proporcionalidad en el marco del DIH equilibra la ventaja militar que se quiere lograr con un ataque a los daños que este ataque puede ocasionar contra la población civil. En una situación de mantenimiento o restablecimiento del orden público, este principio demanda nivelar el riesgo o daño que puede causar una persona a terceros frente a la manera de neutralizarlos, especialmente cuando el derecho a la vida siempre puede verse afectado. Al respecto, la Corte Constitucional (Sentencia T-228, 1994) ha señalado que los derechos constitucionales fundamentales no son absolutos; encuentran límites y restricciones en los derechos de los demás, en la prevalencia del interés general, en la primacía del orden jurídico y en los factores de seguridad, moralidad y salubridad públicos, que no pueden sacrificarse en aras de un ejercicio arbitrario o abusivo de las prerrogativas individuales. 
Por tanto, en el caso del DIH, se produce una ponderación entre la ventaja militar y los dańos incidentales, mientras en el segundo caso, es decir, los derechos humanos, se trata de poner como máximo estándar el derecho a la vida, de ahí que siempre se pretenda evitar un daño inminente o de mayor gravedad. Como consecuencia, el nivel de fuerza autorizado bajo el paradigma del DIH es mucho más letal y en derechos humanos es más restringido.

\section{Estándares de uso en otras situaciones de violencia}

Los Convenios de Ginebra y la Convención Americana sobre Derechos Humanos (1969) no establecen un catálogo de circunstancias en que una muerte producto del uso de la fuerza pueda considerarse justificada por ser absolutamente necesaria en las circunstancias del caso. De ahí que resulte indispensable para los Estados vigilar a sus cuerpos de seguridad, quienes tienen la potestad del uso de la fuerza legítima:

[...] los Estados deben adoptar las medidas necesarias para crear un marco normativo adecuado que disuada cualquier amenaza al derecho a la vida; establecer un sistema de justicia efectivo capaz de investigar, castigar y dar reparación por la privación de la vida por parte de agentes estatales o particulares; y salvaguardar el derecho a que no se impida el acceso a las condiciones que garanticen una existencia digna. (Corte IDH, 2015, párr. 260).

\section{Disyuntiva de la fuerza vinculante del artículo 3 común sobre los ecosistemas criminales}

Los grupos armados no estatales no son "altas partes contratantes" de los Convenios de Ginebra. En 1949, los Estados decidieron que las entidades no estatales no podrían ser parte de los Convenios de Ginebra. Sin embargo, hoy se acepta que el artículo 3 común es vinculante para los grupos armados no estatales, como derecho convencional y como derecho consuetudinario (Murray, 2015).

El mecanismo exacto por el cual el artículo 3 común se vuelve vinculante para un actor que no sea una alta parte contratante en los Convenios de Ginebra es objeto de debate. No obstante, existen algunas explicaciones que tratan de dar respuesta a este planteamiento:

que una entidad que dice representar a un Estado o a partes de este, en particular ejerciendo la soberanía efectiva sobre él, forma parte de las obligaciones internacionales de ese Estado; que luego de la ratificación de los Convenios de Ginebra por un Estado, el artículo 3 común pasa a ser parte del derecho nacional y, por lo tanto, vincula a todos los particulares bajo jurisdicción de ese Estado, incluidos los miembros de un grupo armado no estatal; que el artículo 3 común y otros tratados de derecho humanitario destinados a vincular a partes no estatales en conflictos armados no internacionales son disposiciones convencionales internacionales que lícitamente crean obligaciones para 
terceras Partes, del mismo modo que los tratados pueden, en ciertas circunstancias, crear obligaciones para los Estados que no sean Partes en ellos; que cuando un Estado ratifica un tratado, lo hace en nombre de todos los particulares bajo su jurisdicción, los que por consiguiente son los destinatarios de los derechos y las obligaciones directos que impone el derecho internacional; que deriva de la naturaleza fundamental de las normas [artículo 3 común] y de su reconocimiento por toda la comunidad internacional como el mínimo absoluto necesario para salvaguardar los intereses humanitarios vitales. (CICR, 2019)

Esto se explica porque los grupos armados no estatales también pueden consentir en estar obligados por el artículo 3 común, por ejemplo, mediante la emisión de una declaración unilateral o un acuerdo especial entre las partes en un conflicto armado (Nussberger \& Henderson, 2019).

\section{Conclusiones}

Lo planteado en este artículo implica reconocer, la securitización de la seguridad pública, especialmente en clave del DIH y los derechos humanos, pues los estándares actuales de uso de la fuerza como recurso de necesidad militar en los contextos urbanos no se encuentran regulados más allá de la connotación del CANI dispuesta en el artículo 3 común a los Convenios de Ginebra. Por ese motivo, los servicios de seguridad encuentran limitación y garantías jurídicas en el marco de otras situaciones de violencia, lo que evidentemente los circunscribe a la normativa de la ONU (1979; 1990).

El riesgo de ganar la batalla solo para perder la guerra es significativamente más alto en un conflicto urbano, lo que, por consiguiente, afecta la seguridad y defensa de los Estados. Parafraseando a Álvarez (2017, p. 26) ello se debe a que el problema de la lucha urbana en la actualidad se agudiza si se incluye una megaciudad, un entorno urbano complejo más grande y con poblaciones que superan incluso los diez millones de personas, donde existen intereses políticos locales, regionales e incluso internacionales, además del desafío económico y social que representa el hecho de que las megaciudades son territorios estratégicamente vitales, interconectados a los centros de gravedad nacionales e incluso internacionales.

Por ello, los ecosistemas criminales urbanos tienen un mayor interés actualmente, pues representan para el Estado una amplia y difícil caracterización en el marco de los conflictos actuales. El caso del Estado colombiano no es la excepción, pues el reconocimiento del CANI permite actualmente a los cuerpos de seguridad actuar bajo las reglas de enfrentamiento para el combate terrestre, junto con las reglas de uso de la fuerza, especialmente bajo estándares del DIH.

Cabe recordar que, en Colombia, estas directrices, como objetivos estratégicos, han permitido contar con fórmulas claras para emitir en la actualidad órdenes concretas respecto al uso legítimo, gradual, escalonado y proporcionado de la fuerza, estándares míni- 
mos que deben aplicarse en el desarrollo de las operaciones militares, en particular para confrontar los GAO, GDO y DOT presentes en el territorio nacional.

Dichas reglas claramente constituyen el pilar esencial para desarrollar operaciones en el contexto actual de la amenaza híbrida en Colombia, ya que la amenaza irregular de la guerra no convencional mutó. En consecuencia, es imperativo reconocer el adversario en el ámbito del CANI como aquel que participa directamente en las hostilidades, con el fin de garantizar que los actuales estándares de uso de la fuerza permitan responder a los escenarios urbanos, donde la fuerza pública enfrenta amenazas y riesgos de naturaleza divergente.

Así las cosas, si bien el uso de la fuerza en el marco del DIH puede ser el primer recurso por la ventaja militar, se debe circunscribir a la actividad militar y bélica, pues las exigencias del DIH se rigen por el respeto absoluto al principio de proporcionalidad, distinción, no reciprocidad y limitación. Por ello, la necesidad militar prohíbe causar sufrimientos, heridas o destrucción que no sean necesarios para el logro de fines militares legítimos. Esta prohibición recae sobre quienes participan directamente en las hostilidades bajo la idea de no reciprocidad.

Finalmente, a partir de lo planteado en el artículo, aunque el artículo 3 común no es idóneo para determinar la licitud de la conducción de las hostilidades en escenarios urbanos y en otras situaciones de violencia, es claro que estas acciones también se rigen por las normas específicas del derecho humanitario. En todo caso, es evidente que quienes participan directamente en las hostilidades, hoy por hoy, están en una zona gris respecto a las garantías jurídico-operacionales. De ahí que el marco jurídico que se circunscribe al CANI según el Protocolo II de los Convenios de Ginebra y el derecho internacional consuetudinario sea por ahora el mejor estándar para proteger a la población civil en zonas densamente pobladas, atendiendo a la convergencia de los principios de necesidad y proporcionalidad.

En definitiva, la respuesta que en principio pareciese ser jurídica y normativa no es consecuente con la realidad de los CANI, pues no existe un precepto mundial para dicha regulación. Por ello, el problema debe ser direccionado desde la estrategia política de seguridad y defensa, con el fin de evitar consecuencias negativas para los derechos humanos y el uso de la fuerza por los cuerpos de seguridad. Basta enunciar ejemplos como la batalla de Stalingrado y Aachen durante la Segunda Guerra Mundial, Hue durante Vietnam, Grozny en 1994-1995 y otra vez en 1999-2000, Faluya en 2004 o Sadr en 2008, escenarios en áreas urbanas o zonas densamente pobladas o megaciudades, donde quienes participaban directamente en las hostilidades actuaron sin marco normativo y sin ninguna sanción, lo que dejó como resultado enormes daños. Por el contrario, las operaciones de combate urbano debidamente planeadas pueden crear situaciones en las que los resultados tácticos tengan implicaciones estratégicas respetando los principios del DIH y los derechos humanos. 


\section{Agradecimientos}

Los autores desean agradecer al profesor Mario Lanz Raggio, profesor de la Universidad Antonio Nebrija en Madrid, España, además docente destacado del Instituto Internacional de Derecho Humanitario (San Remo), quien con sus revisiones, observaciones y comentarios enriqueció este artículo.

\section{Declaración de divulgación}

Los autores declaran que no existe ningún potencial conflicto de interés relacionado con el artículo. Este trabajo es parte de los resultados de dos proyectos de investigación: el proyecto "Desafíos contemporáneos para la protección de derechos humanos en escenarios de emergencia y construcción de paz - Fase III", del grupo de investigación Persona, Instituciones y Exigencias de Justicia, categorizado en A1 por Minciencias, vinculado al Centro de Investigaciones Socio Jurídicas de la Universidad Católica de Colombia (CISJUC); y el proyecto "Tendencias evolutivas de las políticas de seguridad y defensa en las Américas", adscrito al grupo de investigación Centro de Gravedad, categorizado en A1, de la Escuela Superior de Guerra "General Rafael Reyes Prieto".

\section{Financiamiento}

Los proyectos de investigación de los cuales surge este artículo son financiados por la Universidad Católica de Colombia y la Escuela Superior de Guerra "General Rafael Reyes Prieto".

\section{Sobre los autores}

Jaime Cubides-Cárdenas es magíster en docencia e investigación con énfasis en ciencias jurídicas y magíster en derecho de la Universidad Sergio Arboleda. Es abogado y especialista en derecho público de la Universidad Autónoma de Colombia. Es estudiante del Doctorado en Derecho de la Universidad Católica de Colombia.

https://orcid.org/0000-0002-6542-6892 - Contacto: jacubides@ucatolica.edu.co

Juan David González Agudelo es magíster en derechos humanos y derecho internacional de los conflictos armados de la Escuela Superior de Guerra (Bogotá) y magíster universitario en seguridad y defensa de la Universidad Antonio Nebrija (Madrid). Es politólogo de la Universidad Pontificia Bolivariana, sede Medellín.

https://orcid.org/0000-0002-4034-003X - Contacto: juand.gonzalez@upb.edu.co Fernanda Navas-Camargo es doctora en educación para integración y el desarrollo humano sostenible, magíster en administración de empresas, abogada y administradora de negocios internacionales. Es investigadora de la Escuela Superior de Guerra "General Rafael Reyes Prieto".

https://orcid.org/0000-0002-4032-7070 - Contacto: johanna.navas@esdegue.edu.co 


\section{Referencias}

Álvarez, C. (2017). Geopolítica vertical y el fenómeno de la urbanización de la guerra en el siglo XXI. Revista Ensayos sobre Defensa y Seguridad, 11, 11-48.

Álvarez, C., \& Rodríguez, C. (2018). Ecosistemas criminales: hábitats para la convergencia y la globalización desviada. Revista Cientifica General José María Córdova, 16(24), 1-30. http://dx.doi. org/10.21830/19006586.352

Comité Internacional de la Cruz Roja (CICR). (1949a, 12 de agosto). Artículo 3 común a los cuatro Convenios de Ginebra. https://bit.ly/3J6VE57

Comité Internacional de la Cruz Roja (CICR). (1949b, 12 de agosto). Convenio IV de Ginebra relativo a la protección debida a las personas civiles en tiempo de guerra. https://bit.ly/3ssj7aT

Comité Internacional de la Cruz Roja (CICR). (1977a, 8 de junio). Protocolo I adicional a los Convenios de Ginebra del 12 de agosto de 1949 relativo a la protección de las víctimas de los conflictos armados internacionales. https://bit.ly/3FpKgyQ

Comité Internacional de la Cruz Roja (CICR). (1977b, 8 de junio). Protocolo II adicional a los Convenios de Ginebra del 12 de agosto de 1949 relativo a la protección de las víctimas de los conflictos armados sin carácter internacional. https://bit.ly/3H66lTG

Comité Internacional de la Cruz Roja (CICR). (2015). Armas explosivas en zonas pobladas. Aspectos humanitarios, jurídicos, técnicos y militares. Editorial CICR.

Comité Internacional de la Cruz Roja (CICR). (2019). Comentario del Convenio de Ginebra I. Editorial CICR.

Constitución Política de Colombia. (1991). Gaceta Constitucional n. ${ }^{\circ} 116$. http://bit.ly/2NA2BRg

Convención Americana sobre Derechos Humanos. (1969, 22 de noviembre). San José de Costa Rica. https:// bit.ly/3J7Nvx8

Corte Constitucional de Colombia. (1994, 10 de mayo). Sentencia T-228. (J. G. Hernández Galindo, M. P.). https://bit.ly/3FlVRz3

Corte Constitucional de Colombia. (2017, 21 de junio). Sentencia C-674. (G. Guerrero Pérez, M. P.). https:// bit.ly/3pldcCu

Corte Interamericana de Derechos Humanos (Corte IDH). (2013, 20 de noviembre). Caso de las comunidades afrodescendientes desplazadas de la cuenca del río Cacarica (Operación Génesis) vs. Colombia. (D. García-Sayán, M. P.). https://bit.ly/32nTuwW

Corte Interamericana de Derechos Humanos (Corte IDH). (2012, 30 de noviembre). Caso Masacre de Santo Domingo vs. Colombia. Sentencia. Excepciones preliminares, Fondo y Reparaciones (D. García-Sayán, M. P.). https://bit.ly/3edcxwJ

Corte Interamericana de Derechos Humanos (Corte IDH). (2015, 17 de abril). Caso Cruz Sánchez y otros vs. Perú. Sentencia. Excepciones preliminares, Fondo y Reparaciones (H. Sierra Porto, M. P.). https:// bit.ly/34wyEfX

Corte Penal Internacional. (2014). Caso ICC-01/04-01/07. The prosecutor v. Germain Katanga y Mathieu Ngudjolo Chui. Primera instancia (M. Perrin de Brichambaut. M. P.).

Cubides, J., Ardila, C., \& González, J. (2019). El uso de la fuerza: recurso de necesidad militar en el Derecho internacional Humanitario bajo el contexto colombiano. En C. Espaliú \& J. Delgado (Coords.), El conflicto y su situación actual: del terrorismo a la amenaza hibrida (pp. 119-132). Thomson Reuters; Editorial Aranzadi.

Heidelberg Institute for International Conflict Research. (2019). Conflict Barometer 2019. https://bit. ly/32eegzw 
Henckaerts, J.-M., \& Doswald-Beck, L. (2007). El derecho internacional humanitario consuetudinario. Editorial CICR.

Hoffman, F. (2009, octubre). Hybrid vs. compound war. Armed Forces Journal. https://indianstrategicknowledgeonline.com/web/4198658.pdf

Ley 800. (2003, 13 de marzo). Por medio de la cual se aprueban la "Convención de las Naciones Unidas contra la Delincuencia Organizada Transnacional" y el "Protocolo para prevenir, reprimir y sancionar la trata de personas, especialmente mujeres y niños, que complementa la Convención de las Naciones Unidas contra la Delincuencia Organizada Transnacional”... Diario Oficial 45131. Congreso de la República de Colombia. https://bit.ly/3GZDnEE

Ley 1801 (2016, 29 de septiembre). Por la cual se expide Código Nacional de Seguridad y Convivencia Ciudadana. Diario Oficial 49949. Congreso de la República de Colombia. https://bit.ly/3mq4QaY

Melzer, N. (2010). Guía para interpretar la noción de participación directa en las hostilidades según el derecho internacional humanitario. Editorial CICR.

Melzer, N. (2019). Derecho Internacional Humanitario una Introducción Integral. Editorial CICR.

Ministerio de Defensa Nacional (Mindefensa). (2015, 25 de abril). Disposición 019 de 2015. Manual de Derecho Operacional para las Fuerzas Militares 3-41. Público (segunda edición). https://bit.ly/3ehlpBn

Ministerio de Defensa Nacional (Mindefensa). (2016a, 22 de abril). Directiva Permanente 015 de 2016. Expedir los lineamientos del Ministerio De Defensa Nacional para caracterizar y enfrentar a los Grupos Armados Organizados (GAO). https://bit.ly/3mu4ZtM

Ministerio de Defensa Nacional (Mindefensa). (2016b, septiembre). Manual Fundamental del Ejército 6-27. Derecho operacional terrestre. https://bit.ly/30PveTU

Ministerio de Defensa Nacional (Mindefensa). (2017a, 28 de septiembre). Resolución 01872. Manual Fundamental del Ejército 3-07. Estabilidad. https://bit.ly/3msS9fD

Ministerio de Defensa Nacional (Mindefensa). (2017b, 28 de septiembre). Resolución 01874. Manual Fundamental del Ejército 3-28. Apoyo de la defensa a la autoridad civil. https://bit.ly/3qrVhJU

Murray, D. (2015). How International Humanitarian Law treaties bind non-State armed groups. Journal of Conflict and Security Law, 20(1), 101-131, https://doi.org/10.1093/jcsl/kru010

Nussberger, B., \& Henderson., C. (2019). The use of force and international law. Journal of Conflict and Security Law, 24(2), 409-412. https://doi.org/10.1093/jcsl/krz009

Organización de las Naciones Unidas (ONU). (1979, 17 de diciembre). Código de conducta para funcionarios encargados de hacer cumplir la ley. https://bit.ly/3JbYK7N

Organización de las Naciones Unidas (ONU). (1990). Principios básicos sobre el empleo de la fuerza y de armas de fuego por los funcionarios encargados de hacer cumplir la ley. https://bit.ly/32nw8rv

Pérez, J. P., \& Acevedo, L. (2010). Crimenes de guerra como violaciones serias del derecho internacional humanitario. Coordinadora Nacional de Derechos Humanos.

Valencia, A. (2013). El Derecho Internacional Humanitario. Alto Comisionado de las Naciones Unidas para los Derechos Humanos.

Werle, G. (2005). Tratado de derecho penal internacional. Tirant Lo Blanch. 